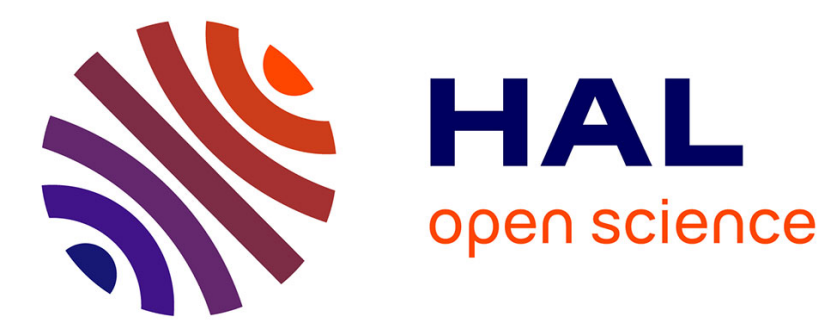

\title{
Facial emotion labeling in language impaired children
}

\author{
Maryse Delaunay - El Allam, Michèle Guidetti, Yves Chaix, Judy Reilly
}

\section{To cite this version:}

Maryse Delaunay - El Allam, Michèle Guidetti, Yves Chaix, Judy Reilly. Facial emotion labeling in language impaired children. Applied Psycholinguistics, 2011, 32 (4), pp.781-798. 10.1017/S0142716411000063 . hal-03265822

HAL Id: hal-03265822

https://hal-normandie-univ.archives-ouvertes.fr/hal-03265822

Submitted on 21 Jun 2021

HAL is a multi-disciplinary open access archive for the deposit and dissemination of scientific research documents, whether they are published or not. The documents may come from teaching and research institutions in France or abroad, or from public or private research centers.
L'archive ouverte pluridisciplinaire HAL, est destinée au dépôt et à la diffusion de documents scientifiques de niveau recherche, publiés ou non, émanant des établissements d'enseignement et de recherche français ou étrangers, des laboratoires publics ou privés. 


\title{
Facial emotion labeling in language impaired children
}

\author{
MARYSE DELAUNAY-EL ALLAM
}

Equipe de Psychologie des Actions Langagières et Motrices, Université de Caen Basse Normandie, Caen, France.

\section{MICHÈLE GUIDETTI,}

Equipe Cognition, Communication et Développement (ECCD), Unité de Recherche Interdisciplinaire Octogone, EA 4156, Université de Toulouse, UTM, Toulouse, France.

\section{YVES CHAIX}

Unité de neurologie pédiatrique, Hôpital des Enfants (Purpan), Toulouse, France.

INSERM, U825, Imagerie cérébrale et handicaps neurologiques, Toulouse, France.

\section{JUDY REILLY}

San Diego State University, CA, USA.

\section{ADDRESS FOR CORRESPONDENCE}

Maryse Delaunay-El Allam, Université de Caen Basse Normandie, PALM, Maison de la Recherche et des Sciences Humaines, Esplanade de la paix, 14032 Caen Cedex, France. E.mail: maryse.delaunay-elallam@unicaen.fr

Tel : 0033231566265

Fax: 0033231566260 


\begin{abstract}
The few studies that have investigated emotion labeling in children with specific language impairment (SLI) have generally focused on global identification performances and appear contradictory. The current study is a fine-grained examination of how children with SLI and typical peers differ in the accuracy of their emotional lexicon use. Children underwent a free labeling task of five basic emotions expressed by still face photographs. Results revealed that children with SLI were less accurate in their label use than typical children. However, pattern of confusions between the two groups differed only by a confusion between sadness and anger displayed by the SLI group. It is argued that this emotion labeling deficiency may rely on semantic fields overlap.
\end{abstract}




\section{SOCIAL AND EMOTIONAL COMPETENCES IN CHILDREN WITH SLI}

Children with specific language impairment (SLI) often encounter difficulties with social integration. Their behavior appears more passive, withdrawn, and reticent in social interaction contexts, as compared with typical peers (Conti-Ramsden \& Botting, 2004; Fujiki, Brinton, Morgan, \& Hart, 1999; Tallal, Dukette, \& Curtis, 1989). Several investigations support these observations, demonstrating for instance that children with SLI are less effective than typically developing age-peers to engage in peer interaction and to manage peer conflicts and reconciliations and further have more negative representations about peers consequences in conflict situations (Botting \& Conti-Ramsden, 2000; Brinton, Fujiki, \& Higbee, 1998; Brinton, Fujiki, Spencer, \& Robinson, 1997; Liiva \& Cleave, 2005; Horowitz, Westlund \& Ljungberg, 2007; Timler, 2008). It has been hypothezised that in association with impaired linguistic skills, poor emotional competencies may contribute to problems with communication in children with SLI, which may lead to negative consequences in social interactions and friendship formation (Brinton, Spackman, Fujiki, Ricks, 2007; Ford \& Milosky, 2003; Spackman, Fujiki, Brinton, Nelson, \& Allen, 2005; Spackman, Fujiki, \& Brinton, 2006; Timler, 2003; Trauner, Ballantyne, Chase, \& Tallal, 1994). For instance, children with SLI encounter more difficulties than their typical peers in understanding social rules of emotion display. Indeed, they display more emotion confusions when trying to infer others' emotional feelings in different social situations (Ford \& Milosky, 2003; Spackman, Fujiki, Brinton, Nelson, \& Allen, 2005; Spackman, Fujiki, Brinton, 2006). Further, children with SLI show less correct responding in indicating when an emotion may be concealed in particular social situations compared to their peers (Brinton, Spackman, Fujiki, Ricks, 2007). However, emotional competencies tested in these studies demand a high level of social cognition. Since little research, up to date, has paid attention to emotion expression understanding in children with SLI, the current study aims to examine further their ability to 
recognize and label emotions conveyed by facial display. Indeed, deficits in perception and understanding of others' facial emotions are frequently highlighted as an explanation for poor social competence in individuals with various developmental disorders including autism (Boraston, Blakemore, Chilvers \& Skuse, 2007; Celani, Battacchi, \& Arcidiacono, 1999; Lacroix, Guidetti, Rogé, \& Reilly, 2009), William syndrome (Kasari, Freeman, \& Hughes, 2001; Lacroix, Guidetti, Rogé, \& Reilly, 2009), learning disabilities (Dimitrovsky, Spector, Levy-Shiff, \& Vakil, 1998; Holder \& Kirkpatrick, 1991; Nabuzoka \& Smith, 1995), as well as specific language impairment (Spackman, Fujiki, Brinton, Nelson, \& Allen, 2005 ; Timler, 2003).

\section{LEXICAL AND SEMANTIC DEFICITS IN SPECIFIC LANGUAGE IMPAIRMENT}

Specific language impairment (SLI) is defined as atypical language development that is believed to differ from a simple developmental delay, and is not associated with any other sensory, motor, cognitive, neurological or psychotic disorders (DSM IV, APA, 2000). SLI is the umbrella term for various types of syndromes that have been classified in several ways (Conti-Ramsden \& Botting, 1999; Korkman \& Häkkinnen-Rihu, 1994; Rapin \& Allen 1988; Van Weerdenbur, Verhoeven, \& Van Balkom, 2006). Language deficits can either affect receptive or expressive abilities, or both. When both production and understanding are impaired, the related term is mixed receptive / expressive SLI. Numerous studies have examined phonological, morphological, or syntactical problems, and have attempted to formulate models to describe and explain them. Children with SLI also encounter lexical and semantic difficulties, since they show a delayed onset of lexical acquisition and long-term deficits in lexical knowledge compared to age-, and gender- matched typically-developing children (Leonard, 1998). Deficits concern the storage and organization of lexical information in lexicon, and/or the access to lexical items in lexicon (Brackenbury \& Pye, 2005), and 
manifest themselves through a more limited lexicon (Watkins, Kelly, Harbers, \& Hollis, 1995; Watkins, Rice, \& Moltz, 1993), word retrieval difficulties (McGregor, 1997; McGregor \& Waxman, 1998), slow naming (Katz, Curtis, \& Tallal, 1992; Lahey \& Edwards, 1996), as well as in frequent errors in naming objects or actions (McGregor, 1997; Lahey \& Edwards, 1999).

Underspecified semantic representations have been shown to contribute to word retrieval failure and to frequent naming errors in children with SLI by McGregor and colleagues. These authors assessed the level of semantic representations in analyzing both drawing and verbal responses, since they tackle common semantic representations. Their results indicated that for both children with SLI and typically developing peers, correct naming was associated with rich semantic representations, whereas naming errors were associated with weak semantic representations (McGregor \& Apple, 2002; McGregor, Friedman, Reilly, \& Newman, 2002; McGregor, Newman, et al., 2002).

Thus, the current study examines whether emotion labeling is also affected by atypical semantic representation, and whether this affects one or several emotion concepts. We hypothesize that semantic representations of emotional labels may be underspecified in children with SLI. More specifically, we expect labeling errors to be more frequent for emotions that share similar semantic features, as, for example, the same valence.

\section{FACIAL EMOTION IDENTIFICATION IN LANGUAGE IMPAIRED CHILDREN}

A few previous studies have investigated the ability of children with language impairments to identify facial emotional expressions. However, their results appear paradoxical, mainly because the populations studied and the methods used differed. For example, Trauner, Ballantyne, Chase, and Tallal (1994) used a forced-choice paradigm whereby participants were required to choose the appropriate emotion label from happiness, anger or sadness to 
identify emotional expressions presented on photographed still faces. Children with SLI from 9 to 13 years-old had similar labeling performances as compared with age-matched control peers. This result was later confirmed by different research teams in kindergarten children. Ford and Milosky (2003) and McCabe \& Meller, (2004) compared the capacity of children with SLI and typical peers to label four emotions (happiness, anger, fear, and sadness) expressed by prototypical facial drawings, or cartoon faces, by asking children to point to the appropriate face corresponding to the given emotional label. Authors observed no significant differences in labeling performances between children with SLI and typical peers. Creusere, Alt and Plante (2004) compared the ability of children with and without SLI to identify four emotions (happiness, anger, sadness, and surprise) expressed through dynamic faces using a 2-forced choice paradigm between two labels. Here again no significant group differences were found. .

However, other studies did not corroborate these results. Dimitrovsky, Spector, Levy-Shiff, and Vakil (1998) compared labeling accuracy in 9 to 12 year-old children $\mathrm{f}$ diagnosed with different types of learning disorders (associated with verbal deficit or not), to the performances of matched typical peers. They used a free labeling task to measure children's ability to identify seven different facial emotional expressions from still faces (happiness, anger, disgust, fear, sadness, surprise, and a neutral expression). Children with verbal deficits were slower and less accurate in identifying facial expressions than typically developing peers. The possibility that the different origins of the learning disabilities account for such differential results can not be excluded here. However, more recently, Spackman and colleagues (2006) revealed parallel results in 5 and 12 year-old language-impaired children using a forced-choice task that required less verbal demand. They explored labeling capacities of 6 emotions (happiness, anger, disgust, fear, sadness, surprise) expressed through still faces, by asking children to point to the appropriate emotion response cards that associated a written 
label and a figurative drawing. The authors also analyzed which emotions were confused. Children with SLI performed more poorly than typical peers in identifying the emotions of disgust and surprise, and more often misidentified disgust as anger and to a lesser extent surprise as fear.

While the results of these studies seem contradictory, it must be noted that the difficulty level of the tasks is highly different in the above mentioned studies. This factor directly influences the capacity of children to perform (Gosselin, 2005). It is possible that the 2- to 4-forcedchoice tasks used in the aforementioned studies made the task too easy for children thus creating a ceiling effect. Inversely, the 6-forced-choice task or the free labeling task among seven emotions requires the use of more elaborative cognitive functions. Indeed, for instance, in order to label the different emotional expressions freely and accurately, children must have knowledge of each emotional label, be able to have rapidly access to the target label in their lexicon, and use it categorically for only one emotional expression. Thus, although this task is more difficult it removes the risk of a ceiling effect. This is the paradigm we chose to employ in the current study. We also included a priming phase prior to the free labeling task, in order to ease children's access to the emotional labels in their lexicon and optimize label retrieval. Finally, in the aforementioned studies, authors generally analyzed children's global scores of correct identification responses. To study emotion understanding, we considered that it would be more effective to focus on the way emotional labels were used by the children, taking into account the exclusivity of their use, and the type of emotional confusion mistakes made. Indeed, as Widen \& Russell hypothesized (2003, 2008), the study of the nature of these mistakes may inform us about the level of meaning being used by the children to produce labels, and may further highlight the emotion semantic fields that overlap. Thus, the close examination of the accuracy of emotion label use and of the patterns of emotion confusions made in children with SLI as compared with controls matched on gender, age and facial 
emotional expression perceptual skills, will allow for testing whether some emotion concepts are more difficult to master for children with SLI than for typical control peers. Such an investigation is important for theoretical reasons and for its clinical implications.

\section{CURRENT ISSUES}

The aim of the current study is to assess and identify what differentiates children with SLI and typical peers in emotional facial expression free labeling skills. Two main issues were investigated:

1) To compare the extent of emotional productive lexicon of children with SLI and typical peers.

2) To examine how children with SLI and typical peers differ in the accuracy of the emotional labels use in comparing: a) correct identification performance; b) the use exclusivity of specific emotional labels, and finally c) the patterns of emotion confusions.

\section{METHOD}

\section{Participants}

Participants of this study were 12 children with specific language impairment (SLI) and 12 additional typically language developing children matched on gender, age and visual perceptual capacities. The group of children with SLI included only one female. Such distribution is in line with medical epidemiologic reports indicating that SLI is mostly represented in males (DSM IV, APA, 2000). The children were recruited to participate in the study after their parent and the certified speech therapist (for the children with SLI) gave written informed consent. 
All the children with SLI were identified by a certified speech therapist as experiencing mixed SLI that affects both receptive as well as expressive skills. They were recruited from a center for language difficulties (Children's Hospital, Purpan, Toulouse, France), where they were diagnosed and were undergoing a speech and language remedial program. The diagnosis of SLI was carried out using standardized tests assessing language understanding and production abilities, after establishing the neurological, motor, cognitive profile. At the time of testing, children with SLI were between 5;6 and 10;5 years of age (mean age $=96.6$ months, $S D=20$ months, see Table 1). As all children with SLI were involved in a speech and language remedial program, this improved their verbal IQ, reaching 74.5 on average $(S D=8.87$, Range $=63-91$, see Table 1). Thus, the children with SLI who were tested in the present study could understand simple instructions such as those used in the present study.

Typically developing children were between 5;6 and 10;9 years of age (mean age $=97.4$ months, $S D=20.9$ months, see Table 1) at the time of testing. They were reported to be developing normal language skills by their teacher and parents and no language difficulties were identified during routine pediatrician visits. Children were recruited from several school establishments in the Toulouse city center in France. All the children were from a middle socio-economic background. Children were matched on one-to-one basis on three criteria: gender, chronological age and emotion perceptual skills (Table 1).

\section{INSERT TABLE 1 ABOUT HERE}

\section{Materials}

The facial stimuli used in the current study were used from the San Diego Affective Facial Expression (Reilly \& Stiles, 2006). They were black-and-white photographs (dimensions: $7 \mathrm{~cm} \times 10 \mathrm{~cm}$ ) of facial expressions. Models included 6 Caucasian adults (4 women and 2 men) who posed while displaying happy, angry, surprised, sad, afraid and neutral expressive faces. All facial expressions retained were first validated by the Facial Action Coding System 
FACS (Ekman, Friesen, \& Hager, 2002) with a certified coder (J.R.) and then by a panel of 35 adults in a pilot study, with a minimal score of $92 \%$ of correct recognition for all facial expressions. Four models ( 2 women and 2 men) were used in the perceptual matching task, and the remaining women were reserved for the free labeling task. In the perception-matching task, photographs were presented in a digital format (JPEG file) directly on a computer screen, while in the labeling task they were presented on laminated cards.

\section{Design and general procedure}

The experimenter began the testing session with a familiarization period during which she spent time conversing with the child until he/she became comfortable. Then, the experimenter invited the child to play with a computerized game realized with Presentation software (version 9.9) and introduced it with the following: "We are going to play together". The testing session included a facial emotion visual matching task (realized in order to match children on the basis of perceptual skills) and the free labeling task of facial emotional expressions.

\section{Emotion perceptual task}

A first task was used as a screening test in order to match children with SLI with typical children on the basis of visual percepual skills of facial emotions. This task consisted of an expressive face-matching task. It was presented as a computerized game using three-forced choices. It began with two training trials to ensure that every child understood the matching principle and how to answer correctly. During these trials the experimenter invited the child to look at a picture (either a dog or a smiley drawing) presented on the top of the computer screen. Then three pictures including the target picture presented previously appeared on the bottom of the screen, while the target picture was still visible on the top of the screen. The 
experimenter invited the child to choose the picture corresponding to the one presented initially. The child responded by pointing to the picture chosen with his/her finger, while the experimenter recorded the response by pressing on the right, middle, or left mouse button.

The formal task began immediately after these training trials. All trials were run according to the following protocol stages. 1) Presentation of an expressive face on the top of the screen. 2) Presentation of three photographs of different persons demonstrating a facial expression (apart from the person displaying the target expression) on the bottom of the screen. Those faces expressed either the target emotional expression, an emotional distractor, or a neutral one. 3) The experimenter asked the child to look at the target person and to choose the one who feels the same, among the three faces presented at the bottom of the screen. The task was comprised of 20 trials (4 trials per basic emotion) with the order of initial expression presentation and the side of presentation counterbalanced for expression type, gender, and person posing. The total number of faces presented was also balanced for each person, both for the initial target expression presentation stage, and for the 3 forced choice presentation stage. Testing trials were carried out in two blocks separated by a 5-min break, during which the child was invited to play with stickers. The computer program used automatically generated one log file collating the responses given by every child.

A global score of correct matching was calculated by accumulating the number of times the child chose the target face so that the maximal score was 20 points (totalling the number of trials).

Typically developing children were matched on the basis of perceptual skills with the twelve children with SLI so that variations in perceptual skills would not affect results. 


\section{Free emotion labeling task}

A free labeling task was used to compare production and use of emotional labels in children with SLI and in typically developing children. Contrary to previous tasks, the current task was not computerized. Children's verbal term productions were recorded manually by an experimenter when cards with different affective facial expressions were presented.

Difficulties with word finding has often been observed in children with SLI (e.g., Fried-Oken, 1987; Kail, Hale, Leonard \& Nippold, 1984; Katz et al., Tallal, 1992; Lahey \& Edwards, 1996; McGregor, 1997; McGregor \& Waxman, 1998). Accordingly, this free labeling task was preceded by a label priming phase in order to avoid any lexicon access bias, and to balance label accessibility in verbal long-term memory in children with SLI and matched controls. This procedure has further been used by Widen \& Russell $(2003,2008)$ during the investigation of emotional labeling in typically developing children. During the priming phase, conventional labels of the relevant emotions were verbally presented 3 times to the children by introducing them with a story in which a character experiences the respective emotions. Primed labels were happy, angry, surprised, sad or afraid (labels were presented in French). The order of term presentation during the prior priming phase was counterbalanced. The free labeling task was then realized with the following instructions: "We are going to play with cards that show the face of a girl. Then you will have to tell me how the girl on the card is feeling". A familiarization labeling sequence with three training trials was carried out prior to recording the child's label productions. This training sequence presented the face of a woman with three different expressions, while testing trials were conducted with an unfamiliar face. The order of presentation of the different affective expressions was counterbalanced. Each emotional expression was presented 3 times so that the total number of trials in the free labeling task reached 15 trials. 


\section{Label production and use analysis}

The different labels produced by the children were classified as a function of their emotional meaning. Non emotional labels ("wicked", "not beautiful”, or "I don't know") as well as ubiquitous labels (such as "Good" or "Bad") were excluded from the analyses. Only emotional labels were retained. They comprised specific terms referring only to one distinct emotion, and non specific terms that indicate an emotional valence (such as "unhappy"), or a level of arousal (such as "excited").

Different types of responsiveness were analyzed and reported in the results. Firstly, the emotional productive lexicon of children with SLI and typical peers was compared through two analyses : 1) a description and a quantification of the different emotional productions; and 2) an estimation of the priming effect on the frequency of primed emotional labels. Secondly, the accuracy of emotions labeling was compared in children with SLI and typical peers via three different analyses : 1) an assessment of correct emotion identification that was realized by adding the number of times children used a specific emotional label in an appropriate fashion and for each emotional expression tested ; 2) a global estimation of the exclusive use of emotional labels produced by adding the number of times specific emotional labels were produced exclusively to identify one particular emotion ; and 3) a description and scoring of the different emotional confusions displayed by children.

\section{Statistical analyses}

The data analyses focused on a systematic comparison between children with SLI and gender-, age- and perceptual- matched controls, both qualitatively in terms of emotional labels production and use, and quantitatively in terms of identification abilities. We conducted either parametric, or non-parametric analyses as a function of the type of dependent variable considered, but always considered children's group as a between subject factor (SLI versus 
typical). All statistical analyses were conducted with an $\alpha$ error set at $\mathrm{p}<.05$. The level of effect size (ES) was also estimated. To do this we report each ANOVA with partial eta squared defined by Cohen (1988) (negligible ES: $\eta_{p}^{2}<.15$, small ES: .15 $\leq \eta_{p}^{2}<.40$, medium ES: $.40 \leq \eta_{\mathrm{p}}^{2}<.75$ and large ES: $\left.\eta_{\mathrm{p}}^{2} \geq .75\right)$. Analyses were conducted using Statistica software $\left(8^{\text {th }}\right.$ version, Statsoft ${ }^{\circledR}$, Tulsa, USA).

\section{RESULTS}

\section{Emotion perceptual skills}

Global visual matching scores were high in children with SLI (Mean=17.1, $S D=2.6$, Range= 11-20), as well as in typical children $($ Mean $=17.2, S D=2.8$, Range $=11-20$, see Table 1$)$. A Mann Whitney U test confirmed that children were accurately matched on the basis of these scores $(U=69, Z=-0.14, p>.05)$. Thus, SLI and matched typical children both demonstrated appropriate visual and cognitive abilities to perceive and recognize emotional facial display.

\section{Emotional productive lexicon}

\section{Emotional productions}

Specific and non specific emotional labels produced (in French) by the children are listed in Table 2. The children, from both SLI and typical groups, produced a total range of 16 different emotional labels. Children with SLI produced 10 different emotional labels, while typically developing children produced 14 different emotional labels. A Mann Whitney U carried out on this data yielded no significant difference between the two groups total number of different emotional labels $(U=47, Z=-1.41, p>.05)$. Furthermore, 8 labels were common between the children with SLI and matched typical peers. These labels included the 5 conventional labels that had been primed in the preliminary phase. 
Priming effect on emotional productions frequency

Because the priming phase could have influencedthe children with SLI and their typical counterparts differently in their frequency of emotional label productions, we performed a 2way ANOVA with children's group as the between subject factor (SLI versus typical) and

priming as the within subject factor (primed labels versus not primed labels). The ANOVA only revealed a main effect of priming $\left[F(1,22)=38.88, p<.0001, \eta_{p}^{2}=.64\right]$, but no interactive effect. As illustrated Figure 1, children from both groups produced labels that had been previously primed 5 times more frequently $(M=10.17, S D=.81)$ than labels that had not been primed $(M=2.46, S D=.61$, Figure 1$)$. Thus, previous priming influenced the production frequency of emotional labels similarly in children with SLI and matched controls.

\section{INSERT FIGURE 1 ABOUT HERE}

Use accuracy of the emotional labels produced

Correct identification of the different emotional expressions

To compare global labeling performances displayed by the children with SLI and typical peers, we conducted a 2-way ANOVA on the scores of correct identification responses, considering children's group as the between subject factor (SLI versus typical) and emotional expressions as the within subject factor (happiness, sadness, surprise, anger, and fear). This analysis yielded no significant differences between children's group, indicating that children with SLI and typical peers displayed similar abilities in correct emotional expression identification when emotional expressions were pooled, as well as when they were considered one by one. 


\section{Exclusive use of the emotional labels produced}

Next, we wanted to examine whether children with SLI and typical matched peers would differ in their use exclusivity of the specific emotional labels. To do so, we computed a 2-way ANOVA on the occurrences of emotional label production, considering children's group as a between subject factor (SLI versus typical) and the exclusivity of emotional labels use as a within subject factor (exclusive versus non exclusive use). A significant interaction effect appeared $\left[F(1,22)=5.47, p=.029, \eta^{2}=.20\right]$., Post hoc matched samples $t$ tests revealed for showed that typical children used emotional labels more often exclusively for only one emotion $(M=9.5, S D=1.28)$, than not exclusively for several emotions $(M=3.5, S D=1.09)$, $[t(11)=2.88, p=.015$, Figure 2]. However, children with SLI used emotional labels as often exclusively for one emotion $(M=5.58, S D=1.28)$, as not exclusively $(M=6.66, S D=1.09)$, $[t(11)=-0.49, p>.05$, Figure 2]. Moreover, $t$ tests for independent samples revealed that children with SLI used emotional labels exclusively significantly less often than typical children did $[t(11)=-2.16, p=.042]$. Thus, these results demonstrate that, although they display similar correct emotion identification performances, children with SLI were less accurate than gender-, age- and perceptual- matched controls, since they used less frequently specific emotional labels in an exclusive fashion.

\section{INSERT FIGURE 2 ABOUT HERE}

\section{Patterns of emotional confusions}

The descriptive matrixes of emotional confusions, illustrated Tables 2 and 3, show that both SLI and typical groups of children did not display the same patterns of emotional confusion. Different types of non-parametric statistical analyses were performed to verify whether SLI and typical children displayed a significantly different number of emotional confusions. 
First, a Mac Nemar test revealed that the group of children with SLI produced more emotion confusion mistakes $(n=32)$ than typical group $(n=17)$ when considering all emotional expressions $\left(\chi^{2}\right.$ Mac Nemar $\left.=4.0, p=.045\right)$. Secondly, Mann Whitney $U$ tests were performed to specify which emotional expressions were confused at different rates in SLI and typical groups by comparing each emotional confusion type in pairs. It was found that both groups often confused fear and surprise. Indeed, children with SLI and typical peers used fear labels to identify surprise $(U=60, Z=.66, p>.05)$, and surprise labels to identify fear equally often $(U=65.5, Z=-0.34, p>.05)$. Nevertheless, more precise observations revealed that within the SLI group, fear labels were used to identify surprise faces by two subjects for a total number of 3 occurrences, but none of the children in the typical group displayed this type of confusion. On the contrary, surprise labels were used to identify fear faces in both groups by 4 subjects, for a total number of 10 occurrences in each group. Thus, while typical children mislabeled only fear faces, children with SLI mislabel surprise as well as fear expressions.

In addition, children with SLI also displayed frequent confusions of emotion between sadness and anger contrary to matched typical children $(U=33.5, Z=2.19, p=.02)$. Contrary to their matched typical children, more than half of the children with SLI mislabeled a sad expression, using terms referring to anger instead of sadness. Indeed, within the SLI group, seven participants used anger labels to identify sad faces for a total occurrence of 14 times (cf. Table 3a), while this type of confusion was made only once in the other group (cf. Table $3 b$ ). Moreover, it is noticeable that a confusion of the reversed type was never observed either within the SLI group or the typical group. Thus the close examination of emotional confusions highlights SLI children's deficits in labeling the negative emotional expression of sadness, and the use of anger labels to identify this negative emotional expression. This suggests that the concepts of these two negative emotions are not mastered and overlap in 6 to 10 years-old children with SLI. 


\section{DISCUSSION}

This study investigated the ability of SLI children to identify facial emotional expressions in a free labelling task, as compared with typically developing children matched on gender, chronological age, and facial emotional expression perceptual skills.

Firstly, results showed that although children with SLI produced fewer emotional label productions than typical children, the difference did not reach significance. This does not corroborate the results of previous studies related to lexical deficits of children with SLI (Brackenbury \& Pye, 2005; Watkins et al., 1995; Watkins et al., 1993). The difference with these other studies could be explained by the fact that, in the current study, free production of emotional labels was facilitated by the priming phase of expected specific emotional labels. Secondly, consistent with previous studies, global correct identification of facial emotional expressions appeared similar in children with SLI and matched typical children (Trauner et al., 1993; Creusere et al., 2004). However, a closer analysis of label use accuracy and emotional confusions highlighted deficiencies in children with SLI. Indeed, compared to matched controls, they used less frequently emotional labels in an exclusive way. Therefore, although children with SLI were able to access different emotional labels in their lexicon and produce them, they used labels less accurately than typically developing peers.

In addition, children with SLI and typical peers did not show the same confusion patterns between emotions. Both groups often confused fear and surprise, whereas children with SLI also frequently confused sadness with anger. These two types of confusions could rely either on perceptual similarities, or on semantic deficits in the acquisition of the underlying emotional concepts, or both. The first confusion between fear and surprise was reported by different research teams in children as well as in adults (Gosselin, 1995; Gosselin \& Kirouac, 1995; Russell \& Bullock, 1985). Gosselin and Simard (1999) further showed that the distinction between those expressions in children directly depends on the number of facial 
action units that are distinct in both facial patterns. According to these authors, the confusion between surprise and fear may be due to perceptual similarities between the two patterns. Nevertheless, since SLI children aged 5 to 12 years of age are not known to confuse these two negative emotions more frequently than typically developing children (Spackman et al., 2005), this confusion could be explained by an overlap of the semantic representation between fear and surprise.

Indeed, contrary to fear and surprise facial expressions, there are not many common action units between sadness and anger facial patterns. Also, since the children enrolled in the current study were matched on emotional facial perceptual skills, their perceptual skills were similar. Consequently, we can conclude that the semantic knowledge of anger and sadness emotion concepts is deficient in 6 to 10 year old SLI children, as compared with their typically developing peers. The fact that the children with SLI used conventional labels referring to anger in order to identify sadness may be explained by their lacking of words for sadness expression and/or by the fact that the semantic category of anger concept is underspecified. The results obtained by Spackman and colleagues support this second suggestion. Indeed, they found that children with SLI from 5 to 12 years old were more likely to mislabel disgust facial expression as anger than their typical peers, whereas both groups misidentified anger as disgust as frequently (Spackman et al., 2005). Moreover, in another study exploring others' feelings inference in children with SLI aged from 5 to 12 years of age and typical peers, they reported that the former inferred anger instead of sadness more often than the latter (Spackman, Fujiki \& Brinton, 2006).

It is noticeable that the confusion patterns evinced in children with SLI concern emotion categories with the same negative valence, and are also frequently observed in younger children (Spackman et al., 2005, 2006), as for example, confusions between sadness and anger, which are recurrent in typically developing kindergartners, but disappears by the age of 
5-6 years of age when typical children make the distinction between sadness and anger concepts (Durand, Gallay, Seigneuric, Robichon, \& Baudouin, 2007; Gosselin, 2005; Herba, Landau, Russell, Ecker, \& Phillips, 2006; Russell \& Widen, 2002; Vicari, Reilly, Pasqualetti, Vizzotto, \& Caltagirone, 2000; Widen \& Russell, 2003, 2008). Widen \& Russell (2003, 2008) described the systematic pattern of emotion label production and confusions in typically developing children in an American sample. They reported that the first emotional labels produced between the age of 2 to 5 years-old are "happy", "angry" and "sad", and that their underlying semantic categories are initially broad (or underspecified) and then become progressively narrow. For instance, the label "angry" is first produced in order to identify any negative expressions including sadness and is then used increasingly more specifically. Thus, taking into account both the singular confusion pattern of children with SLI from 6 to 10 and the characteristics of the typical way emotional terms are acquired, we can hypothesize that emotion labeling deficiencies evinced in children with SLI may simply correspond to a delay in emotion conceptual development.

This would be in line with Leonard's conclusions (1998) about linguistic deficiencies observed in children with SLI, which proposes that many of the difficulties with registration, organization of new words in lexicon, and specifying the meaning of a new word, reflect more of a delay in acquisition than the presence of deviant processes.

\section{IMPLICATIONS FOR CLINICAL ASSESSMENT, AND TREATMENT AND}

\section{CONCLUSIONS}

The results of the present study suggest that emotion labeling confusions revealed in SLI are discrete rather than general, and that these may simply be due to a developmental delay. As such emotional labeling abilities of SLI children could be improved by training programs focusing on semantic enrichment. Indeed, it has been shown experimentally that word 
meaning improvement is input dependant in children with SLI as well as in typically developing peers (Conti-Ramsden \& Jones, 1997; Rice, Oetting, Marquis, Bode, \& Pae, 1994). Furthermore, McGregor and Leonard (1989) showed evidence of improvement in naming after SLI children underwent training treatment and learned new semantic information about target words. More recently, Capone and McGregor $(2004,2005)$ stated that the use of gestures (manual and facial mimics) may be especially relevant to enrich semantic knowledge of children with SLI, since gestures are known to enhance word learning in conveying salient semantic information in typically developing children (Capone \& McGregor, 2005; McNeil, Alibali \& Evans, 2000; Guidetti \& Nicoladis, 2008; Gullberg, De Boot, \& Volterra, 2008), and, because, they involve non verbal modalities that may be compatible with the relative strengths of children with SLI.

To conclude, we suggest speech and language therapists assess the semantic knowledge of emotion concepts and determine the different types of semantic relationships the children with SLI have developed within and between emotion labels, particularly for emotions with negative valence. Then, treatment tools for semantic knowledge enrichment may be applied to emotion concepts underspecified, in order to improve emotion understanding and thus decrease the level of confusion. However, further research is needed first to examine how emotion labeling develops in typically developing children in the French population, and secondly to verify whether children suffering from receptive, expressive, or mixed language impairment would display different abilities in emotion labeling.

\section{ACKNOWLEDGEMENTS}

Authors are grateful with the children and their parents who accepted to participate in the study. They thank the teachers, schoolmasters, as well as the students (Master's Degree of 
Psychology, Toulouse 2 University, France), for their help in recruiting children and conducting the experiment. A special thank is given to Isabelle Barry and Juliette Elie for their help in collecting data with the children with SLI. This work was supported by a grant from French National Research Agency (ANR) to the "Emotion" project ( $\mathrm{n}^{\circ}$ 05-4_43763). The first author thanks Delphine Picard for her constructive advice on earlier drafts, Nathalie Goubet and Loveday Newmann for English improvement, and anonymous reviewer for his (her) suggestions and positives comments.

\section{REFERENCES}

American Psychiatry Association (Eds.). (2000). Diagnosis and Statistical Manual of mental disorders, Fourth edition, Text Revision. Washington, DC: APA.

Boraston, Z., Blakemore, S.J., Chilvers, R., \& Skuse, D. (2007). Impaired sadness recognition is linked to social interaction deficit in autism. Neuropsychologia, 45, 1501-1510.

Botting, N., \& Conti-Ramsden, G. (2000). Social and behavioural difficulties in children with language impairment. Child Language Teaching \& Therapy, 16, 105-120.

Brackenbury, T., \& Pye, C. (2005). Semantic deficits in children with language impairments: Issues for clinical assessment. Language Speech \& Hearing Services in Schools, 36, 516.

Brinton, B., Fujiki, M., \& Higbee, L. M. (1998). Participation in cooperative learning activities by children with language impairment. Journal of Speech Language and Hearing Research, 41, 1193-1206.

Brinton, B., Fujiki, M., Spencer, J.C., \& Robinson, L.A., (1997). The ability of the children with specific language impairment to access and participate in an ongoing interaction. Journal of Speech, Language, and Hearing Research, 40, 1011-1025. 
Brinton, B., Spackman, M.S., Fujiki, M., \& Ricks, J. (2007). What should Chris say ? The ability of children with specific language impairment to recognize the need to dissemble emotions in social situations. Journal of Speech Language and Hearing Research, 50, 798-811.

Capone, N., \& McGregor, K.K. (2004). Gesture development: A review for clinical research practices. Journal of Speech, Language, and Hearing Research, 47, 173-186.

Capone, N., \& McGregor, K. K. (2005). The effect of semantic representation on toddlers' word retrieval. Journal of Speech, Language, and Hearing Research, 48, 1468-1480.

Celani, G., Battachi, M. W., \& Arcidiacono, L. (1999). The understanding of the emotional meaning of facial expressions in people with autism. Journal of Autism and Developmental Disorders, 29, 57-66.

Cohen, J. (1988). Statistical power analysis for the behavioral sciences. Mahwah, NJ: Lawrence Erlbaum Associates, publishers.

Conti-Ramsden, G., \& Jones, M. (1997). Verb use in specific language impairment. Journal of Speech, Language, and Hearing Research, 40, 1298-1313.

Conti-Ramsden, G., \& Botting, N. (1999). Classification of children with specific language impairment: Longitudinal considerations. Journal of Speech, Language and Hearing Research, 42, 1195-1204.

Conti-Ramsden, G., \& Botting, N. (2004). Social difficulties and victimization in children with SLI at 11 years of age. Journal of Speech, Language, and Hearing Research, 47, $145-161$.

Creusere, M., Alt, M., \& Plante, E. (2004). Recognition of vocal and facial cues to affect in language-impaired and normally-developing preschoolers. Journal of Communicative Disorders, 37, 5-20. 
Dimitrovsky, L., Spector, H., Levy-Shiff, R., \& Vakil, E. (1998). Interpretation of facial expressions of affect in children with learning disabilities with verbal or nonverbal deficits. Journal of Learning Disabilities, 31, 286-292.

Durand, K., Gallay, M., Seigneuric, A., Robichon, F., \& Baudouin, J. Y. (2007). The development of facial emotion recognition: The role of configural information. Journal of Experimental Child Psychology, 97, 14-27.

Ekman, P., Friesen, W. V., \& Hager, J. C. (2002). Facial action coding system. Research Nexus. Network Research Information.

Ford, J. A., \& Milosky, L. M., (2003). Inferring emotional reactions in social situations: differences in children with language impairment. Journal of Speech, Language, and Hearing Research, 46, 21-30.

Fried-Oken, M. (1987). Qualitative examination of children's naming skills through test adaptations. Language, Speech, and Hearing Services in Schools, 18, 206-216.

Fujiki, M., Brinton, B., Morgan, M., \& Hart, C. H. (1999). Withdrawn and sociable behavior of children with language impairment. Language, Speech, and Hearing Services in Schools, 30, 183-195.

Fujiki, M., Spackman, M.P., Brinton, B., \& Illig, T. (2008). Ability of children with language impairment to understand emotion conveyed by prosody in a narrative passage. International Journal of Language \& Communication Disorders, 43, 330-345.

Gosselin, P. (1995). Le développement de la reconnaissance des expressions faciales des émotions chez l'enfant. [The development of facial emotion expressions recognition in children]. Revue Canadienne des Sciences du Comportement, 27, 107-119.

Gosselin, P. (2005). Le décodage de l'expression faciale des émotions au cours de l'enfance. [Facial emotional expression decoding during childhood]. Canadian Psychology, 46 (3), 126-138. 
Gosselin, P., \& Kirouac, G. (1995). Le décodage de prototypes émotionnels faciaux. [Facial emotional prototypes decoding]. Revue Canadienne de Psychologie Experimentale, 49, 313-329.

Gosselin, P., \& Simard, J. (1999). Children's knowledge of facial expressions of emotions: Distinguishing fear and surprise. The Journal of Genetic Psychology, 160, 181-193.

Guidetti, M. \& Nicoladis, E. (2008). Introduction to special issue : gestures and communicative development. First Language, 28, 107-115.

Gullberg, M., De Boot, K. \& Volterra, V. (2008). Gestures and some key issues in the study of language development. Gesture, 8, 149-179.

Herba, C. M., Landau, S., Russell, T., Ecker, C., \& Phillips, M. L. (2006). The development of emotion-processing in children: effects of age, emotion, and intensity. Journal of Child Psychology and Psychiatry, 47, 1098-1106.

Holder, H. B., \& Kirkpatrick, S. W. (1991). Interpretations of emotion from facial expressions in children with and without learning disabilities. Journal of Learning Disabilities, 24, $170-177$.

Kail, R., Hale, C. A., Leonard, L. B., \& Nippold, M. A. (1984). Lexical storage and retrieval in language-impaired children. Applied Psycholinguistics, 5, 37-49.

Kasari, C., Freeman, S. F., \& Hughes, M. A. (2001). Emotion recognition by children with Down Syndrome. American Journal of Mental Retardation, 106, 87-100.

Katz, W., Curtis, S., \& Tallal, P. (1992). Rapid automatized naming and gesture by normal and language impaired children. Brain and Language, 43, 623-641.

Korkman, M., \& Häkkinnen-Rihu, P. (1994). A new classification of developmental language disorders. Brain \& Language, 47, 96-116. 
Lacroix, A., Guidetti, M., Rogé, B., \& Reilly, J. (2009). Recognition of emotional and nonemotional facial expressions: A comparison between Williams syndrome and autism. Research in Developmental Disabilities, 30, 976-985.

Lahey, M., \& Edwards, J. (1996). Why do children with specific language impairment name pictures more slowly than their peers? Journal of Speech, Language, and Hearing Research, 39, 1081-1098.

Lahey, M., \& Edwards, J. (1999). Naming errors of children with specific language impairment. Journal of Speech, Language, and Hearing Research, 42, 195-205.

Leonard, L. B. (1998). Children with specific language impairment. Cambridge, MA: The MIT Press.

Liiva, C., \& Cleave, P. (2005). Roles of initiation and responsiveness in access and participation for children with specific language impairment. Journal of Speech, Language, and Hearing Research, 48, 868-883.

McCabe, P.C., \& Meller, P.J. (2004). The relationship between language and social competence : How language impairment affects socials growth. Psychology in the Schools, 41, 313-321.

McGregor, K. (1997). The nature of word-finding errors of preschoolers with and without word-finding deficits. Journal of Speech and Hearing Research, 40, 1232-1244.

McGregor, K., \& Leonard, L. B. (1989). Facilitating word-finding skills of language-impaired children. Journal of Speech and Hearing Disorders, 54, 141-147.

McGregor, K., \& Apple, A. (2002). On the relation between mental representation and naming in a child with specific language impairment. Clinical Linguistics and Phonetics, 16, 1-20. 
McGregor, K., Friedman, R. M., Reilly, R., \& Newman, R. M. (2002). Semantic representation and naming in young children. Journal of Speech, Language, and Hearing Research, 45, 332-346.

McGregor, K., Newman, R. M., Reilly, R., Capone, N. (2002). Semantic representation and naming in children with specific language impairment. Journal of Speech, Language, and Hearing Research, 45, 998-1014.

McGregor, K., \& Waxman, S. R. (1998). Object naming at multiple hierarchical levels: A comparison of preschoolers with and without word-finding deficits. Journal of Child Language, 25, 419-430.

McNeil, N. M., Alibali, M. W., \& Evans, J. (2000). The role of gesture in children's comprehension of spoken language: Now they need it, now they don't. Journal of Nonverbal Behavior, 24, 131-149.

Nabuzoka, D., \& Smith, P.K. (1995). Identification of expressions of emotions by children with and without learning disabilities. Learning Disabilities Research and Practice, 10(2), 91-101.

Rapin, I., \& Allen, D. (1988). Syndrome in developmental dysphasia and adult aphasia. In F. Plum (Ed.), Language, Communication and the brain, New York: Raven Press.

Reilly, J., \& Stiles, J. (2006). SANAFE. San Diego. Unpublished manuscript.

Rice, M., Oetting, J., Marquis, J., Bode, J., \& Pae, S. (1994). Frequency of input effects on word comprehension of children with specific language impairment. Journal of Speech and Hearing Research, 37, 106-122.

Russell, J. A., \& Bullock, M. (1985). Multidimentional scaling of emotional facial expressions: Similarities from preschoolers to adults. Journal of Personality and Social Psychology, 48, 1290-1298. 
Russell, J. A., \& Widen, S. C. (2002). A label superiority effect in children's categorization of facial expressions. Social Development, 11, 30-52.

Spackman, M.S., Fujiki, M., \& Brinton, B. (2006). Understanding emotions in context: The effects of language impairment on children's ability to infer emotional reactions. International Journal of Language \& Communication Disorders, 41, 173-188.

Spackman, M.S., Fujiki, M., \& Brinton, B., Nelson, D., \& Allen, J. (2006). The ability of children with language impairment to recognize emotion conveyed by facial expression and music. Communication Disorders Quarterly, 26, 131-143.

Tallal, P., Dukette, D., \& Curtis, S. (1989). Behavioral/emotional profiles of preschool language-impaired children. Development and Psychopathology, 1, 51-67.

Timler, G.R. (2003). Reading emotion cues: Social communication difficulties in pediatric populations. Seminars in speech and language, 24(2), 121-130.

Timler, G.R. (2008). Social knowledge in children with language impairments: Examination of strategies, predicted consequences, and goals in peer conflict situations. Clinical Linguistics \& Phonetics, 22 (9), 741-763.

Trauner, D. A., Ballantyne, A., Chase, C., \& Tallal, P. (1994). Comprehension and expression of affect in language impaired children. Journal of Psycholinguistic Research, 22, 445452.

Van Weerdenburg, M., Verhoeven, L., \& Van Balkom, H. (2006). Towards a typology of specific language impairment. Journal of Child Psychology and Psychiatry and allied disciplines, 47, 176-189.

Vicari, S., Reilly, J. S., Pasqualetti, P., Vizzotto, A., \& Caltagirone, C. (2000). Recognition of facial expressions of emotions in school-age children : the intersection of perceptual and semantic categories. Acta Paediatrica, 89, 836-845. 
Watkins, R., Rice, M. L., \& Moltz, C. (1993). Verb use by language-impaired and normally developing children. First Language, 13, 133-143.

Watkins, R., Kelly, D., Harbers, H., Hollis, W. (1995). Measuring childrens' lexical diversity differentiating typical and impaired language learners. Journal of Speech, Language, and Hearing Research, 28, 1348-1355.

Widen, S. C., \& Russel, J. A. (2003). A closer look at preschoolers' freely produced labels for facial expressions. Developmental Psychology, 39, 114-128.

Widen, S. C., \& Russel, J. A. (2008). Children acquire emotion categories gradually. Cognitive Development, 23, 291-312. 
Table 1. Individual characteristics of the children with SLI and matched typically-developing peers

\begin{tabular}{|c|c|c|c|c|c|c|c|c|c|}
\hline \multicolumn{6}{|c|}{ Children with SLI } & \multicolumn{4}{|c|}{ Matched peers } \\
\hline Subjects & Gender & Age & $\begin{array}{c}\text { Verbal } \\
\text { IQ }\end{array}$ & $\begin{array}{c}\text { Non Verbal } \\
\text { IQ }\end{array}$ & $\begin{array}{l}\text { Emotion } \\
\text { perceptual } \\
\text { score }\end{array}$ & Subjects & Gender & Age & $\begin{array}{l}\text { Emotion } \\
\text { perceptual } \\
\text { score }\end{array}$ \\
\hline 1 & Male & $5 ; 6$ & 74 & 100 & 11 & $1^{\prime}$ & Male & $5 ; 6$ & 11 \\
\hline 2 & Female & $5 ; 10$ & 80 & 113 & 17 & $2^{\prime}$ & Female & $5 ; 10$ & 15 \\
\hline 3 & Male & $6 ; 8$ & 64 & 86 & 20 & $3^{\prime}$ & Male & $6 ; 9$ & 20 \\
\hline 4 & Male & $7 ; 2$ & 71 & 92 & 15 & $4^{\prime}$ & Male & $7 ; 2$ & 14 \\
\hline 5 & Male & $7 ; 2$ & 69 & 80 & 16 & $5^{\prime}$ & Male & $7 ; 2$ & 17 \\
\hline 6 & Male & $7 ; 2$ & 76 & 105 & 18 & $6^{\prime}$ & Male & $7 ; 3$ & 17 \\
\hline 7 & Male & $8 ; 9$ & 76 & 95 & 15 & $7^{\prime}$ & Male & $8 ; 6$ & 18 \\
\hline 8 & Male & $8 ; 11$ & 63 & 92 & 20 & $8^{\prime}$ & Male & $9 ; 2$ & 20 \\
\hline 9 & Male & $9 ; 3$ & 64 & 95 & 20 & $9^{\prime}$ & Male & $9 ; 2$ & 18 \\
\hline 10 & Female & $9 ; 9$ & 91 & 95 & 17 & $10^{\prime}$ & Female & $10 ; 2$ & 16 \\
\hline 11 & Male & $10 ; 0$ & 80 & 93 & 17 & $11^{\prime}$ & Male & $10 ; 0$ & 16 \\
\hline 12 & Male & $10 ; 5$ & 86 & 100 & 19 & $12^{\prime}$ & Male & $10 ; 9$ & 20 \\
\hline
\end{tabular}


Table 2. Emotional labels produced in French (English translation) by SLI and typically developing children.

\begin{tabular}{|c|c|c|}
\hline & Children with SLI & Peers \\
\hline \multirow[t]{8}{*}{ Common } & *Contente (Happy) & *Contente (Happy) \\
\hline & *Surprise (Surprised) & *Surprise (Surprised) \\
\hline & *En colère $($ Angry) & *En colère $($ Angry) \\
\hline & *Triste $(S a d)$ & *Triste $(S a d)$ \\
\hline & *A peur (Afraid) & *A peur (Affraid) \\
\hline & Sourire/souriante (Smiling) & Sourire/souriante (Smiling) \\
\hline & Fâchée (Angry) & Fâchée (Angry) \\
\hline & Pas contente (Unhappy) & Pas contente (Unhappy) \\
\hline \multirow[t]{8}{*}{ Own } & Boude (Sulking) & - \\
\hline & Excitée (Excited) & - \\
\hline & - & Heureuse (Glad) \\
\hline & - & Joyeuse (Cheerful) \\
\hline & - & Etonnée (Surprised) \\
\hline & - & Malheureuse (Sad) \\
\hline & - & Enervée (Irritated) \\
\hline & - & Fait les gros yeux (Angry) \\
\hline
\end{tabular}

* Conventional labels previously primed 
Table 3a. Matrix of emotional confusions displayed in SLI Children $(\mathrm{n}=12)$.

Emotional expression presented

\begin{tabular}{cccccc}
\hline Confusion mistakes & Happiness & Surprise & Anger & Sadness & Fear \\
\hline Happiness & - & 1 & 0 & 0 & 1 \\
Surprise & 0 & - & 0 & 0 & $\mathbf{1 0}$ \\
Anger & 0 & 1 & - & $\mathbf{1 4}$ & 1 \\
Sadness & 0 & 0 & 0 & - & 1 \\
Fear & 0 & $\mathbf{3}$ & 0 & 0 & - \\
\hline \hline
\end{tabular}

Table 3b. Matrix of emotional confusions displayed in typically developing children $(n=12)$

\begin{tabular}{cccccc}
\hline \hline & \multicolumn{5}{c}{ Emotional expression presented } \\
\hline Confusion mistakes & Happiness & Surprise & Anger & Sadness & Fear \\
\hline Happiness & - & 3 & 0 & 0 & 2 \\
Surprise & 0 & - & 0 & 0 & $\mathbf{1 0}$ \\
Anger & 0 & 0 & - & $\mathbf{1}$ & 0 \\
Sadness & 0 & 0 & 0 & - & 0 \\
Fear & 0 & 0 & 0 & 1 & - \\
\hline \hline
\end{tabular}




\section{FIGURE CAPTION}

Figure 1. Total number of production occurrences (Mean \pm Standard Error) of primed and non primed emotional labels in SLI typically-developing children). ${ }^{* * *}: p<.0001$.

Figure 2. Total number of occurrences of emotional label use (Mean \pm Standard Error) either exclusively for one emotional expression, or in a non exclusive way in children with SLI and typical children. $*: p \leq .05$. 


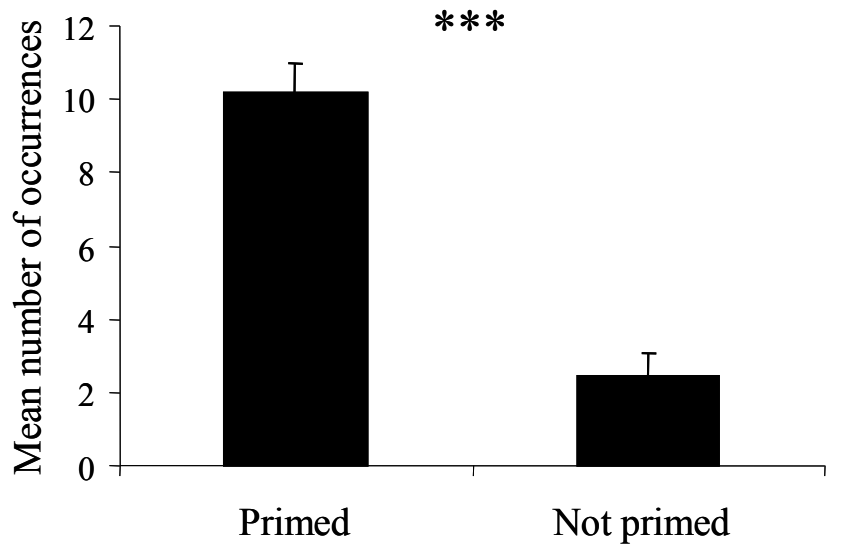

Figure 1. 


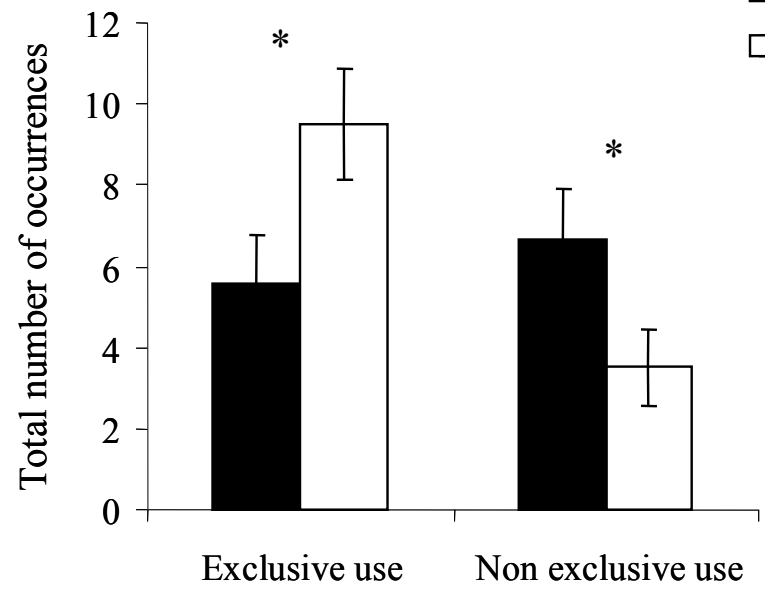

- Children with SLI

$\square$ Typical children 